\title{
Intranasal tooth: Incidental finding in two cases
}

\author{
Mohammad Akheel ${ }^{1,2, *}$, Deepti Chablani ${ }^{3}$ \\ ${ }^{1}$ Consultant Oral and maxillofacial surgeon, Chennai, Tamilnadu, India \\ ${ }^{2}$ Correspondence- Block 5, 4H, VGN laparasiene, Nolambur, Mogappair west, Chennai -600037, T.N. India \\ ${ }^{3}$ Junior Registrar, Dept. of oral \& maxillofacial surgery, Terna Dental College\& hospital, Mumbai, Maharashtra, India \\ Email address: \\ drakheelomfs@gmail.com (M. Akheel),drdeepti.omfs@gmail.com (D. Chablani)
}

To cite this article:

Mohammad Akheel, Deepti Chablani. Intranasal Tooth: Incidental Finding in two Cases. International Journal of Medical Imaging. Special Issue: New Technologies in Medical Imaging. Vol. 3, No. 1-1, 2015, pp. 1-4. doi: 10.11648/j.ijmi.s.2015030101.11

\begin{abstract}
Ectopic eruption of a tooth with its impaction in the nasal cavity is a rare phenomenon. Detailed radiographic evaluation of such patients often reveals surprising things which cannot be expected like incidental intranasal tooth in our cases. This is usually seen in syndromic patients who are associated with cleft lip and palate. They can arise throughout the mid face including the nasal cavity, hard palate, condyle of mandible, orbit and maxillary antrum. They may be placed vertically, horizontally or inverted in position. Sometimes they may erupt normally in the oral cavity and sometimes due to ectopic eruption of these teeth they may be impacted in nasal floor. These teeth have atypical crown and root. We report here 2 cases of non syndromic patients who had supernumerary tooth impacted within the nasal floor with discussion of etiology, complications, diagnosis and treatment approach.
\end{abstract}

Keywords: Intranasal Tooth, Supernumerary, Endoscope

\section{Introduction}

Ectopic eruption of teeth is a rare clinical phenomenon. In literature there is only 30 cases reported till date. ${ }^{1-3}$ They can arise throughout the mid face including the nasal cavity, hard palate, condyle of mandible, orbit and maxillary antrum. ${ }^{4}$ Nasal teeth are associated with clinical symptoms like facial pain, epistaxis, rhinitis, nasal obstruction, headache and naso-lacrimal duct obstruction. ${ }^{5,} 6$ However, these symptoms are not always present in all the patients.

In this article, we report 2 cases, where intra nasal tooth was incidental finding without any other congenital defect or syndrome. Common clinical and radiological presentation, etiology, complications and treatment of intra nasal tooth are discussed here.

\section{Case Reports}

\subsection{Case 1}

A 46 year old male patient reported to department of emergency with history of road traffic accident. Clinical examination revealed multiple abrasions of face, right hematoma of cheek and circumorbital ecchymosis. Patient was non syndromic and had a complaint of mild nasal discharge occasionally and did not seek any treatment previously. Radiological investigations were done which included CT brain and Paranasal sinus view (PNS) of skull. CT brain revealed normal brain parenchyma. CT PNS revealed normal bone continuity of facial skeleton with a radiopaque tooth like structure in the nasal floor on left side situated between nasal septum and inferior turbinate. This was surrounded by granulation tissue (Fig 1). As all the teeth in maxilla were present and there was no fracture, this was provisionally diagnosed as supernumerary tooth which was impacted in the nasal floor. Trans- nasal endoscopic surgery was planned to remove this ectopic tooth under general anesthesia. Trans-nasal endoscopy was introduced from the left nostril to remove the supernumerary ectopic tooth. The tooth was found to be completely embedded by nasal mucosa. So an incision of the nasal floor was made. After localizing the tooth, periosteum was incised and tooth was removed with a forceps from same nostril (Fig 2). Nasal mucosa was sutured with a resorbable material. It was confirmed as supernumerary tooth. Patient was kept on postoperative medication of tab.taxim-O $200 \mathrm{mg}$ tid, tab. Metranidozole $400 \mathrm{mg}$ tid and tab. Diclofenac bid for 5 days and was symptomless on follow up for 4 months. 


\subsection{Case 2}

A 49-year-old female reported to department of oral \& maxillofacial surgery for extraction of right lower molar tooth and had left nasal obstruction with a mucus discharge from 1 month. On examination, she had grossly decayed mandibular molar with all other teeth periodontally compromised. Patient was non syndromic. Rest of her medical history was non contributory. CT PNS revealed a white radiopaque tooth like structure in the floor of the nasal cavity on right side surrounded by granulation tissue (Fig 3).Since there was no history of trauma, this was provisionally diagnosed as an ectopic tooth. Tran's nasal endoscopy was performed under general anesthesia from right nostril to extirpate this ectopic tooth and degranulate the tissue. This malformed tooth like structure was then confirmed as supernumerary tooth with histological examination. Patient was kept on nasal decongestants for 2 weeks and tab. taxim-o $200 \mathrm{mg}$ tid, tab. Metranidozole 400 $\mathrm{mg}$ tid and tab. Diclofenac $50 \mathrm{mg}$ bid for 5 days. Patient was symptomless on followup for 3 months.

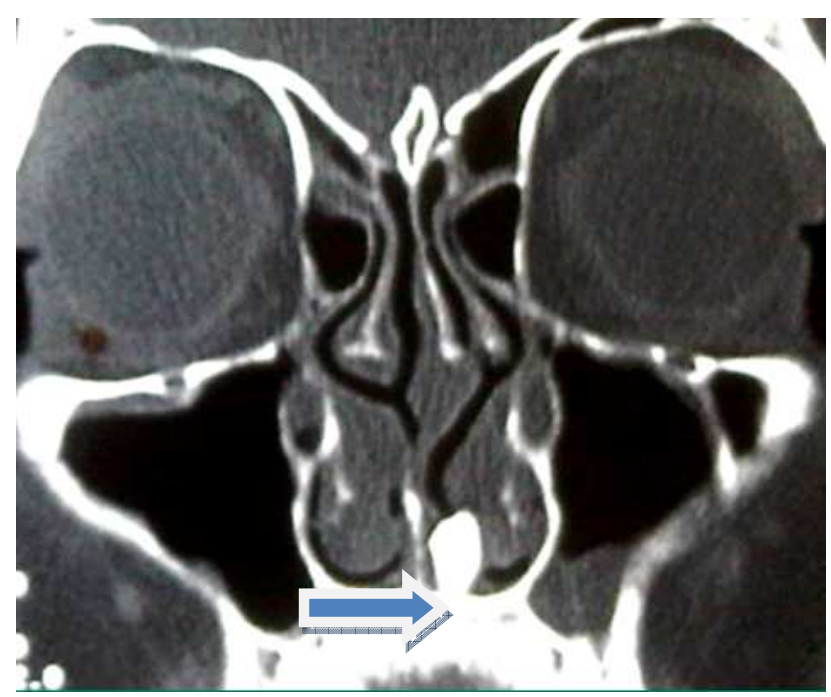

Fig 1. Radiopaque tooth like structure in the nasal floor on left side

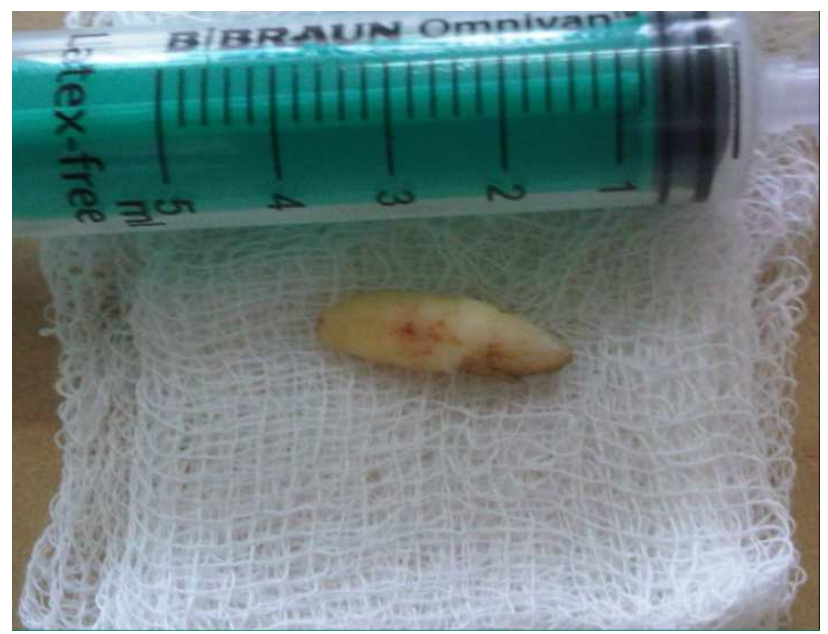

Fig 2. Tooth removed

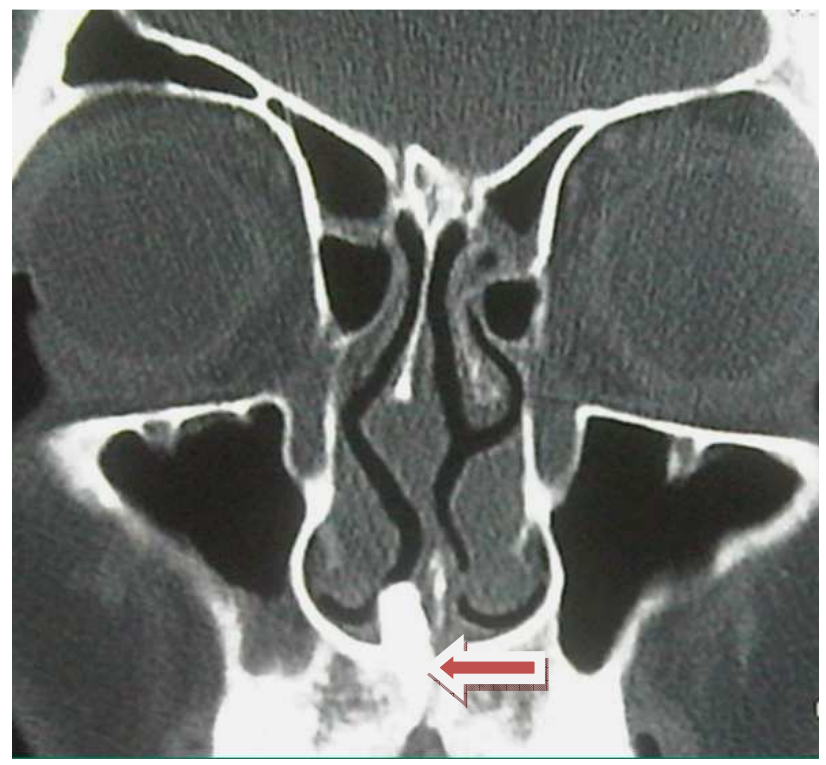

Fig 3. Radiopaque tooth like structure in the floor of the nasal cavity on right side

\section{Discussion}

The German poet Goethe in 1797 was the first to report a case of a tooth in the nose. ${ }^{7}$ Supernumerary tooth are very rare condition in non syndromic patients with an incidence of $0.1 \%$ to $1 \%$ of the population. ${ }^{8}$ They are most common in between maxillary central incisors called as mesiodens. The position of these supernumerary teeth may vary. They may be placed vertically, horizontally or inverted in position. Sometimes they may erupt normally in the oral cavity and sometimes due to ectopic eruption of these teeth they may be impacted in nasal floor. These teeth have atypical crown and root. These teeth usually remain asymptomatic when erupted normally or may cause a variety of signs and symptoms, including facial pain, nasal obstruction, headache, anterior epistaxis, foul-smelling rhinorrhea, external nasal deformities, and naso lacrimal Duct obstruction or may get secondarily infected when they are not erupted and impacted in nasal floor or intranasal. ${ }^{6,9}$ Major complications of these nasal teeth include rhinitis, septal deviations and perforations and naso-oral fistula. ${ }^{10}$

Supernumerary teeth either develop from epithelial remnants of third tooth bed that arises from the dental lamina or from splitting of the permanent bud itself. It is also thought that the development of these teeth is a reversion of the dentition of extinct primates which had three pairs of incisors. ${ }^{8}$ Although the cause of ectopic growth of these teeth is not well understood, it is thought that any obstruction at the time of tooth eruption secondary to crowded dentition, persistent deciduous teeth, or exceptionally dense bone may cause these teeth to get impacted or dislodged in the nasal cavity or nasal floor. Other proposed etiologic factors are genetic predisposition, developmental disturbances and anomalies such as cleft lip and palate,Gardnersyndrome, clediocranial dysostosis and any periapical pathologies such as cysts or trauma. ${ }^{11}$ 
The diagnosis of nasal teeth is made on the basis of clinical and radiographic findings. Clinically, an intranasal tooth may be palpated as a mass in the nasal cavity through the labial vestibule but not always if it is inside the bone. Radiographic investigations like CT PNS and orthopantomogram may be helpful. CT is useful to evaluate the depth of the eruption site and location of the tooth in accordance with other teeth. They reveal a radiopaque mass like structure in nasal cavity or floor. In our case, the teeth were located at the junction of nasal floor and nasal cavity in between the nasal septum and inferior turbinate. However, the CT findings of tooth like structure with a centrally located pulp cavity are highly differentiating features that help to confirm the diagnosis. ${ }^{11}$

The differential diagnosis of nasal teeth includes radiopaque foreign body, anterior rhinolith, any inflammatory lesions due to syphilis, tuberculosis, or fungal infection with intra nasal calcification, benign tumors including osteoma, odontoma and enchondroma, malignant tumors, such as chondrosarcoma and osteosarcoma. $^{12}$

Removal of nasal teeth is generally advocated to resolve the symptoms and prevent further complications. When a nasal tooth is dislocated in nasal cavity it is easier to remove by endoscopy approach but when the tooth has bony socket in the floor of the nose, it may be extremely difficult to extract. In this case an intra-oral approach may be required with removal of the bone around the tooth so that the tooth can be retrieved. Lee et al performed a successful extraction of 13 cases of intra nasal tooth with endoscope. In our case since the tooth was in intra nasally with no bony socket endoscopy was done and the tooth was removed successfully in both the cases. The best time to remove the nasal tooth is after the roots of the other permanent teeth have completely formed, to avoid inadvertent injury to them during their development. ${ }^{14-20}$

\section{Conclusion}

Ectopic and supernumerary teeth occur in a wide variety of sites. Incidental finding of nasal tooth can be deceiving as nasal foreign body. Careful examination, skilled radiological evaluation and perfect anatomical knowledge can differentiate the uncommon entity of nasal tooth from others pathological or congenital entity. Successful diagnosis and treatment of nasal tooth can prevent complications and facilitate safe removal.

\section{Legends}

1] CT PNS reveal intranasal tooth on left side

2] Endoscopic removal of tooth

3] CT PNS reveal intranasal tooth on right side.

\section{Abbreviations}

CT- computed tomography

PNS- paranasal sinus view

\section{References}

[1] Kirmeier R, Truschnegg A, Payer M, Malyk J, Daghighi S, Jakse N. The supernumerary nasal tooth. International journal of oral and maxillofacial surgery 2009;38:1219-1222.

[2] Lin IH, Hwang CF, Su CY, Kao YF, Peng JP. Intranasal tooth: report of three cases. Chang Gung medical journal 2004;27:385-389.

[3] Nisa L, Giger R. Ectopic Tooth in the Maxillary Sinus. New England Journal of Medicine 2011;365:1232-1232.

[4] Lee JH. A nasal tooth associated with septal perforation: A rare occurrence. European archives of oto-rhino-laryngology 2006;263:1055-1056.

[5] Alexandrakis G, Hubbell RN, Aitken PA. Nasolacrimal duct obstruction secondary to ectopic teeth. Ophthalmology 2000;107:189-192.

[6] Chen A, Huang JK, Cheng SJ, Sheu CY. Nasal teeth: report of three cases. American journal of neuroradiology 2002;23:671-673.

[7] HITSCHLER WJ. Nasal teeth: report of a case. Archives of Otolaryngology—Head \& Neck Surgery 1938;28:911.

[8] Thawley SE, Laferriere KA. Supernumerary nasal tooth. The Laryngoscope 2009;87:1770-1773.

[9] Smith RA, Gordon NC, De Luchi SF. Intranasal teeth: report of two cases and review of the literature. Oral Surgery, Oral Medicine, Oral Pathology 1979;47:120-122.

[10] El-Sayed Y. Sinonasal teeth. Journal of otolaryngology 1995;24:180-180.

[11] Moreano EH, Zich DK, Goree JC, Graham SM. Nasal tooth. American journal of otolaryngology 1998;19:124.

[12] Wurtele P, Dufour G. Radiology case of the month: a tooth in the nose. Journal of otolaryngology 1994;23:67-67.

[13] Lee FP. Endoscopic extraction of an intranasal tooth: a review of 13 cases. The Laryngoscope 2009;111:1027-1031.

[14] Martinson F, Cockshott WP. Ectopic nasal dentition. Clinical radiology 1972;23:451-454.

[15] Smith, Richard A., Newton C. Gordon, and Stephen F. De Luchi. "Intranasal teeth: report of two cases and review of the literature." Oral Surgery, Oral Medicine, Oral Pathology 47.2 (1979): 120-122.

[16] Kim, Dae Hyung, et al. "Endoscopic removal of an intranasal ectopic tooth." International journal of pediatric otorhinolaryngology 67.1 (2003): 79-81

[17] Yeung, K. H., and K. H. Lee. "Intranasal tooth in a patient with a cleft lip and alveolus." The Cleft palate-craniofacial journal 33.2 (1996): 157-159.

[18] Johnson, A. P. "A case of an intranasal canine tooth." The Journal of Laryngology \& Otology 95.12 (1981): 1277-1279. 
[19] Spencera, M. G., and A. D. Couldery. "Nasal tooth." The Journal of Laryngology \& Otology 99.11 (1985): 1147-1150.
[20] Erkmen, Nilgün, Seval Ölmez, and Metin Önerci. "Supernumerary tooth in the maxillary sinus: case report." Australian dental journal 43.6 (1998): 385-386. 